\title{
Diagnostic value of distal colonic polyps for prediction of advanced proximal neoplasia in an average-risk population undergoing screening colonoscopy
}

Maite Betés Ibáñez, MD, PhD, Miguel A. Muñoz-Navas, MD, PhD, José M. Duque, MD, PhD, Ramón Angós, MD, PhD, Elena Macías, MD, José Carlos Súbtil, MD, PhD, Maite Herraiz, MD, PhD, Susana de la Riva, MD, PhD, Miguel Delgado-Rodríguez, MD, MPH, Miguel A. Martínez-González, MD, MPH

Current affiliations: Department of Gastroenterology, University Clinic, and Department of Epidemiology and Public Health, School of Medicine, University of Navarra, Pamplona, Spain, and Division of Preventive Medicine and Public Health, University of Jaén, Jaén, Spain.

\section{BACKGROUND}

For colorectal cancer screening, the predictive value of distal findings in the ascertainment of proximal lesions is not fully established. The aims of this study were to assess distal findings as predictors of advanced proximal neoplasia and to compare the predictive value of endoscopy alone vs. combined endoscopic and histopathologic data.

\section{METHODS}

Primary colonoscopy screening was performed in 2210 consecutive, average-risk adults. Age, gender, endoscopic (size, number of polyps), and histopathologic distal findings were used as potential predictors of advanced proximal neoplasms (i.e., any adenoma $\geq 1 \mathrm{~cm}$ in size, and/or with villous histology, and/or with severe dysplasia or invasive cancer). Polyps were defined as distal if located in the descending colon, the sigmoid colon, or the rectum. Those in other locations were designated proximal.

\section{RESULTS}

Neoplastic lesions, including 11 invasive cancers, were found in 617 (27.9\%) patients. Advanced proximal neoplasms without any distal adenoma were present in $1.3 \%$ of patients. Of the advanced proximal lesions, 39\% were not associated with any distal polyp. Older age, male gender, and distal adenoma were independent predictors of advanced proximal neoplasms. The predictive ability of a model with endoscopic data alone did not improve after inclusion of histopathologic data. In multivariate logistic regression analysis, the predictive ability of models that use age, gender, and any combination of distal findings was relatively low. The proportion of advanced proximal neoplasms identified if any distal polyp was an indication for colonoscopy was only $62 \%$.

\section{CONCLUSIONS}

A strategy in which colonoscopy is performed solely in patients with distal colonic findings is not effective screening for the detection of advanced proximal neoplasms in an average-risk population. 


\section{INTRODUCTION}

Most colorectal cancers (CRC) develop from adenomas, ${ }^{1-3}$ which have a long, asymptomatic phase during which they are detectable and curable. Excision of colorectal adenomas reduces the incidence and the mortality of CRC., ${ }^{2,4-11}$ Therefore, CRC fulfills the criteria for benefit from screening. ${ }^{12}$

In 1996, the United States Preventive Services Task Force recommended screening of asymptomatic adults over 50 years of age with either flexible sigmoidoscopy (FS) or fecal occult blood tests (FOBT) ${ }^{13}$ These recommendations now are endorsed by the American Cancer Society, ${ }^{14}$ the World Health Organization, ${ }^{15}$ and by virtually all medical and surgical professional societies concerned with digestive diseases. ${ }^{16,17} \mathrm{~A}$ positive FS or FOBT result is an indication for colonoscopy. The continuing high mortality rates for patients with $\mathrm{CRC}$, together with two large studies that demonstrate that FS fails to identify a substantial proportion of proximal lesions, ${ }^{18,19}$ have led many specialists to regard reliance on FS or FOBT alone as screening tests would be as wrong as mammography of a single breast in screening for breast cancer. ${ }^{12}$ A more detailed assessment of the costeffectiveness of alternative screening procedure ${ }^{20}$ has led to somewhat surprising conclusions that may favor colonoscopy as a primary test. ${ }^{21}$ However, cost is a major limitation to screening, and a more thorough assessment of the predictive value of findings derived from FS to ascertain proximal lesions is needed before accepting colonoscopy as a primary screening modality. Direct comparisons of distal colon examinations vs. colonoscopy are useful to determine the potential additional benefit of examination of the entire colon. Most studies of the association between distal and proximal neoplasia are compromised by selection bias, including specific subgroups. ${ }^{22-35}$ Only studies wherein colonoscopy is offered as a primary screening procedure can appropriately address this issue. Currently, such data that are available derive from 3 studies that comprise relatively few cases ${ }^{36-38}$ and two large studies carried out in the United States. ${ }^{18,19}$ These large studies from the United States assess the usefulness of applying endoscopic and histopathologic findings in the distal colon to predict the likelihood of finding advanced proximal neoplasms. However, the value of endoscopic distal findings alone has not been compared with the predictive power of combined distal endoscopic and histopathologic data. Additional assessments of the relative importance and predictive value of the findings in the distal colon are required to guide clinical decision making.

The primary aim of this study was to determine the diagnostic utility of distal colonic polyps for detecting advanced proximal colonic neoplasms (APN) in an average-risk population undergoing primary screening colonoscopy in a Mediterranean country. A secondary objective was to compare the predictive value of distal endoscopic findings alone with combined endoscopic and histopathologic data.

\section{PATIENTS AND METHODS}

\section{Study design}

The study design was a retrospective analysis of asymptomatic, average-risk adults who were consecutively referred for screening colonoscopy to a university medical center endoscopy unit between 1988 and 1998. The study protocol was approved by a central human-rights committee, and written consent was required in all cases before colonoscopy. 


\section{Patients}

Participants were included in the study if they presented to our clinic for a routine health evaluation and if they were considered to be at average risk for CRC after a medical interview. Our clinic is a private center that attracts patients from throughout Spain. The patients were referred to the endoscopy unit by specialists in internal medicine working in a health evaluation unit in our center. The policy for general health evaluation specifies colonoscopy for all patients older than 40 years. This policy was established in 1988, before the publication of American Gastroenterological Association guidelines for CRC screening.16 Patients were excluded if they had undergone colonoscopy or sigmoidoscopy in the previous 5 years or reported hematochezia, change in bowel habit, or persistent abdominal or rectal pain. Other exclusion criteria were age less than 40 years or greater than 90 years; iron deficiency anemia; weight loss; history of colon polyps or cancer; a first-degree relative with CRC; a history of breast or uterine cancer, inflammatory bowel disease, abdominal radiation, colonoscopy, or barium enema within the previous 5 years, performed for any indication; and use of anticoagulant medication. Patients who had an incomplete colonoscopy $(2.2 \%)$ also were excluded from the analysis.

\section{Study procedures and definitions}

Colonoscopies were performed by staff gastroenterologists (7) or gastroenterology fellows (in their third or fourth year of fellowship) under the supervision of a staff gastroenterologist. All polyps visualized were removed by standard electrosurgical snare polypectomy.

The following endoscopic findings were assessed: (1) location of the polyp(s) or cancer (endoscopist-estimated polyp location on withdrawal of the colonoscope by using landmarks and length of insertion tube within the patient), (2) number of polyps, and (3) polyp size (when seen intact or first removed). Size was confirmed by measuring the maximum diameter of the specimen when using an opened biopsy forceps as a visual guide.

Polyps were defined as distal if located in the descending colon, sigmoid colon, or rectum; polyps in any other segment were designated proximal. Standard methods were used for histopathologic processing and analysis of colorectal polyps. ${ }^{39,40}$ All specimens were reviewed by a pathologist with special expertise in GI pathology. When there was uncertainty, especially for advanced lesions, the case was reviewed at an intradepartment meeting and a diagnosis was made by consensus.

Patients with multiple polyps were categorized according to the polyp with largest diameter, the most atypical histology (villous, tubulovillous, tubular), and the most severe grade of dysplasia. ${ }^{41}$

An 'advanced neoplasm' was defined as any adenoma $1 \mathrm{~cm}$ or greater in size, and/or with a villous (or tubulovillous) morphology, and/or with high-grade dysplasia or invasive cancer. Patients with intramucosal carcinoma or carcinoma in situ were classified as having high-grade dysplasia. Invasive cancer was defined as the invasion of malignant cells beyond the muscularis mucosa. ${ }^{39}$

\section{Statistical analysis}

Logistic regression ${ }^{42}$ was used to identify independent predictors of APN (any adenoma $\geq 1 \mathrm{~cm}$ in size, and/or with villous or tubulovillous morphology, and/or with highgrade dysplasia or invasive cancer). Univariate logistic regression analyses were performed to 
determine candi-date variables (i.e., those found to be significant at the level $p<0.25$ ) for the subsequent multivariate logistic regression analysis, which was conducted to identify those variables with significant independent effects after adjusting for the effects of each of the other variables. Because the latter analysis was considered definitive, there was no need to correctp values to recognize that there was multiple testing of data arising from individual patients. Age, gender, and endoscopic and combined endoscopic and histopathologic data for distal polyps were entered as independent variables. Endoscopic data included two variables: number of polyps $(0,1$, $2, \geq 3$ ) and maximum size (no polyp, $\leq 5 \mathrm{~mm}, 69 \mathrm{~mm}, \geq 10 \mathrm{~mm}$ ). Combined endoscopic and histopathologic data included the following: histopathologic classification (nonpolyp, hyperplastic, nonadvanced adenoma $\leq 5 \mathrm{~mm}$, nonadvanced adenoma $>5$ and $<10$ $\mathrm{mm}$, and advanced neoplasm) and number of adenomas $(0,1,2, \geq 3)$. Age and genderadjusted odds ratios (OR) for APN were calculated in two different logistic regression models that analyzed the following: (1) endoscopic distal findings and (2) combined distal endoscopic and histopathologic data. That the models adequately fit the data was checked with the Hosmer-Lemeshow goodness-of-fit test. The ability of the models to predict the existence of APN was assessed by estimation of the proportion of cases correctly predicted by each model, by calculating the area under the receiver operating characteristic (ROC) curve. ${ }^{43}$

The diagnostic yield of different screening strategies was studied based upon distal findings by means of sensitivity, positive likelihood ratio, positive predictive value (PPV), and number of complete colonoscopies needed with each strategy. ${ }^{44}$

A brief meta-analyses encompassing this and other relevant studies ${ }^{18,19}$ was conducted (results are stated in the discussion section). Meta-analytic summary statistics were calculated based on the methods in Takkouche et al. ${ }^{45}$

\section{RESULTS}

Screening colonoscopy was performed in 2210 consecutive average-risk patients (mean age $57.9 ; 74.6 \%$ men). Recruitment methods were routine health evaluation (1547 patients, $70.0 \%$ ) and followup of a stable medical problem (663 patients, 30.0\%). There were 178 patients $(8.05 \%)$ who were older than 70 years, and $445(20.14 \%)$ were from 40 to 49 years of age. Colonic polyps were detected in $825(37.3 \%)$ and neoplastic lesions in $617(28 \%)$ patients. Advanced neoplasms were found in 156 patients $(7 \%)$. Invasive carcinoma was detected in 11 patients. All of these lesions were identified before there was apparent extracolonic spread of the disease.

Among 56 patients (2.5\%) with APN, 22 (39.3\%) had no index distal polyp, 33 (58.9\%) had at least one index distal adenoma, and 19 (33.9\%) had at least one advanced distal neoplasm (Table 1). None of the 56 patients with APN in this study had hyperplastic distal polyps alone. In 144 patients, all distal colonic polyps were completely destroyed during resection and histopathologic data could not be obtained. Only one of these patients $(1.8 \%)$ had an APN.

\section{Diagnostic yield of different screening strategies based upon distal findings}

The use of more flexible criteria for the definition of a positive sigmoidoscopy improved diagnostic sensitivity (for detection of patients with APN) (Table 2). However, the use of more flexible criteria also was associated with a larger proportion of patients undergoing sigmoidoscopy who are referred for subsequent colonoscopy. 
The proportion of patients with various distal findings who had APN (Table 3, PPV) serves to clarify the effectiveness of each screening model.

The PPV for APN was higher in patients with advanced distal adenomas (16.0\%: 95\% CI $[10.1,24.1])$ than in those without a distal adenoma $(1.3 \%$ : 95\% CI $[0.8,2.0])$. Similar findings were observed when patients with distal polyps $10 \mathrm{~mm}$ or greater in diameter (PPV, 16.3\%: 95\% CI [10.1, 25.2]) were compared with patients without an index polyp (PPV, 1.4\%: 95\% CI $[0.9,2.1])$. Screening strategies in which a colonoscopy would be indicated in either of these groups would detect $30.4 \%$ to $33.9 \%$ of patients with APN but would necessitate colonoscopy in only $4.7 \%$ to $5.4 \%$ of patients screened by FS (Table 2).

The increase in sensitivity of screening strategies in which colonoscopy would be indicated for patients with small polyps or small nonadvanced distal adenomas $(>5$ and $<10 \mathrm{~mm}$ ) was related not only to the larger proportion of patients who would undergo colonoscopy (from $4.7 \% / 5.4 \%$ to $12.2 \% / 10.8 \%$; Table 2 ), but also to a higher PPV in these groups (PPV, 6.7\%; Table 3) compared with those without distal polyps.

The PPV was virtually identical among patients with diminutive $(\leq 5 \mathrm{~mm})$ distal tubular adenomas (PPV, 1.2\%: 95\% CI[0.2, 4.6]) or diminutive ( $\leq 5 \mathrm{~mm}$ ) polyps (PPV, $1.7 \%$ : 95\% CI $[0.8,3.7]$ ) and those without any distal adenoma (PPV, 1.3\%: 95\% CI $[0.8,2.0]$ ) or any distal polyp (PPV, 1.4\%: 95\% CI[0.9, 2.1]). The increase in sensitivity in screening strategies that indicated colonoscopy for these groups could be accounted for almost exclusively by the larger fraction of patients in these groups undergoing colonoscopy (respectively, 20.4\% and 30.2\%; Table 2).

\section{Predictors of advanced proximal neoplasms}

In univariate analyses, age, gender, and endoscopic and histopathologic characteristics of distal polyps were considered potential predictors of APN $(\mathrm{p}<0.25)$.

In multivariate analyses, age and gender were independent predictors of APN $(p<0.05)$. For each year over 40 years of age, the risk increased by $5 \%$ (Table 4 ). The size of distal polyps was found to be the best endoscopic predictor of APN after adjustment for age and gender (Table 4, model A). Combining histopathologic and endoscopic findings (Table 4, model B) led to high ORs for advanced distal adenomas but also for nonadvanced small adenomas (6-9 $\mathrm{mm}$ in size). Distal lesions $5 \mathrm{~mm}$ or less in size (polyps in model A and adenomas in model B) were not found to be independently associated with a significantly greater risk of APN, unless they were multiple $(\geq 3)$.

The addition of any distal finding to age and gender increased the proportion of patients correctly predicted by the models (Table 5). It is noted that the areas under the ROCs for «any distal polyp greater than $5 \mathrm{~mm}$ in size" in the endoscopic model, for «any distal adenoma" in the combined model, and for maximum predictive potential in each of the endoscopic and combined models were significantly greater than the area under the ROC for the baseline (age and gender only) model. However, maximum area under the ROC was always lower than $80 \%$, regardless of the number of variables included in the multivariate model. Negligible differences in the predictive value (area under ROC) were found when only endoscopic data were considered vs. when comparable histopathologic data were added to build the models. 


\section{DISCUSSION}

This is the third study of the use of colonoscopy as a primary screening procedure in a large number of verage-risk adults ${ }^{18,19}$ and the first study conducted outside the United States. Because the study included consecutive colonoscopies in average-risk patients, who freely came to our clinic for a routine health evaluation, the results apply to decision making regarding the use of colonoscopy as a primary screening modality in the general population.

Age and gender were independent risk factors for APN. For each year of age after 40 years, the risk increased by 5\% (after adjustment for gender and distal findings). This estimate is similar to that found in other studies. ${ }^{19}$ Our clinic is a private institution, and many of our patients have private health insurance. This may be the reason for so many men in the study population (74.6\%). Men are known to have an increased age-related risk for colon neoplasia. Over a lifetime, women have a risk of CRC similar to that of men (because they live 5-7 years longer). Although men are known to be at increased risk of colorectal neoplasia, specific differences regarding APN have not been fully established. $^{19,46,47}$

Information on the prevalence of isolated APN was not available until recently. ${ }^{18,19}$ In the present study, patients with no distal adenomas had a risk of APN of $1.3 \%$, a proportion similar to that reported recently for the United States. Consistent with other studies, ${ }^{18,19,48-52}$ the data from the present study show that $40 \%$ of APN (22 of 56) would not have been detected if only the distal colon had been examined, even if FS were followed by colonoscopy when any index distal polyp (hyperplastic or adenoma) was found (Table 1).

Three studies have evaluated the predictive ability of lesions in the distal colon for the risk of APN (Table 6). Summarizing the sensitivity of these studies, $61.1 \%$ of patients with APN $(95 \% \mathrm{CI}[54.9,68.0])$ had at least one index distal polyp, and 50.1\%: 95\% $\mathrm{CI}[43.8,57.4]$ had at least one index distal adenoma.

To estimate the probability of APN, considering distal polyp characteristics, age, and gender together increases the predictive ability, but the area under the ROC was lower than $80 \%$ for all models that stratify patients according to different distal findings. The area under the curve can be directly interpreted as the predicted probability of a test to classify correctly a pair of patients, one with and one without the disease (APN in the present study). This highlights the limitations of findings at FS in predicting APN. The predictive ability of models that included endoscopic data alone was similar to that observed in models that also included histopathologic data. These results support the screening strategy proposed by Stern et al., ${ }^{53}$ which provides comprehensive CRC screening in a single visit by converting from sigmoidoscopy to colonoscopy, depending on distal endoscopic findings. This strategy may reduce the costs of traditional endoscopic screening. ${ }^{54}$

Imperiale et al. ${ }^{19}$ found a significant association between hyperplastic distal polyps and APN. Our results, however, confirm those of other studies ${ }^{18,32,55-59}$ that show that hyperplastic polyps are not predictors of APN. Results differ when the predictive value of different characteristics of distal adenomas were studied in multivariate anal yses. ${ }^{24-27,29,33-35,46,58,60-64}$ The results of the current study are consistent with those of previous studies that demonstrate the importance of advanced distal neoplasms as a 
marker of APN. In fact, pooling of our results with those of previous studies ${ }^{18,19}$ shows homogeneity for tubular adenoma (combined OR 2.96: 95\% CI[2.16, 4.05]) and advanced neoplasms (combined OR 6.43: 95\% CI[4.34, 9.52]). Our data show that patients with diminutive tubular adenomas $(\leq 5 \mathrm{~mm})$ at FS are not at significantly increased risk for APN. If these patients were excluded, the sensitivity of distal examination for detection of APN would decrease to less than $50 \%$ (48.2\% in the present study: 95\% CI[35.1, 61.3]).

The present study has some limitations. First, although the procedures performed remained essentially unchanged over the 10 years of the study, some heterogeneity across time can be expected. Second, there is a possibility of self-selection bias, because the study included patients who exhibited healthseeking behavior. However, there is not sufficient evidence that such behavior modifies the effect of the variables studied. Third, distal colonoscopic findings were used as a surrogate for findings at sigmoidoscopy. The descending colon may not be reached with a sigmoidoscope, or the examination may be limited by suboptimal bowel preparation. Therefore, the present study provides an estimate of the maximum predictive ability of sigmoidoscopy. Fourth, the data alone may not be sufficient for deciding which technique is best for primary CRC screening. Other information, such as the expense and complications of colonoscopy and the natural history of advanced neoplasms, also are relevant. The use of colonoscopy to screen asymptomatic individuals for CRC is feasible and may be the best alternative for identification of patients who may benefit from early detection and removal of potentially malignant lesions. The data from the present study highlight some of the limitations of FS as a primary CRC screening test. The study found that many patients with APN would not be identified by FS and that the risk of APN is associated with increasing age and male gender. If a primary goal of screening is the detection and removal of advanced adenomas, colonoscopy offers more effective screening than sigmoidoscopy.

\section{ACKNOWLEDGMENTS}

The authors thank Cristina Carretero, Elena Santamaría, and the GI staff of the University Clinic of Navarra for their assistance in conducting this study. The authors also thank Dr. David Lieberman for his critical evaluation of the manuscript.

\section{REFERENCES}

1. Winawer SJ, Zauber AG, O’Brien MJ, Gottlieb LS, Sternberg SS, Stewart ET, et al, The National Polyp Study. 1. Design, methods, and characteristics of patients with newly diagnosed polyps. Cancer 1992;70(Suppl 5):1236-45.

2. Winawer SJ, Zauber AG, Ho MN, O’Brien MJ, Gottlieb LS, Sternberg SS, et al. Prevention of colorectal cancer by colonoscopic polypectomy. The National Polyp Study Workgroup. N Engl J Med 1993;329:1977-81.

3. Morson BC. The evolution of colorectal carcinoma. Clin Radiol 1984;35:425-31.

4. Mandel JS, Bond JH, Church TR, Snover DC, Bradley GM, Schuman LM, et al. Reducing mortality from colorectal cancer by screening for fecal occult blood. Minnesota Colon Cancer Control Study. N Engl J Med 1993;328:1365-71. 
5. Kronborg O, Fenger C, Worm J, Pedersen SA, Hem S, Bertelsen K, et al. Causes of death during the first 5 years of a randomized trial of mass screening for colorectal cancer with fecal occult blood test. Scand J Gastroenterol 1992; 27:47-52.

6. Selby JV, Friedman GD, Quesenberry CP, Weiss NS. A case-control study of screening sigmoidoscopy and mortality from colorectal cancer. N Engl J Med 1992;326:653-7.

7. Selby JV, Friedman GD, Quesenberry CP, Weiss NS. Effect of fecal occult blood testing on mortality from colorectal cancer: a case-control study. Ann Intern Med 1993;118:1-6.

8. Newcomb PA, Norfleet RG, Storer BE, Surawicz T, Marcus PM. Screening sigmoidoscopy and colorectal cancer mortality. J Natl Cancer Inst 1992;84:1572-5.

9. Winawer SJ, Flehinger BJ, Schottenfeld D, Miller DG. Screening for colorectal cancer with fecal occult blood testing and sigmoidoscopy. J Natl Cancer Inst 1993;85:1311-8.

10. Muller AD, Sonnenberg A. Prevention of colorectal cancer by flexible endoscopy and polypectomy. A case-control study of 32,702 veterans. Ann Intern Med 1995;123:904-10.

11. Towler B, Irwig L, Glasziou P, Kewenter J, Weller D, Silagy C. A systematic review of the effects of screening for colo-rectal cancer using the faecal occult blood test, hemoccult. BMJ 1998;317:559-65.

12. Podolsky DK. Going the distance. The case for true colorectalcancer screening. N Engl J Med 2000;343:207-8.

13. Woolf SH. Screening for colorectal cancer. In: Guide to clinical preventive services: report of the U.S. Preventive Services Task Force. Baltimore: Williams and Wilkins; 1996. p. 89-103.

14. Byers T, Levin B, Rothenberger D, Dodd GD, Smith RA. American Cancer Society guidelines for screening and surveillance for early detection of colorectal polyps and cancers: update 1997. CA Cancer J Clin 1997;47:154-60.

15. Shike M, Winawer SJ, Greenwald PH, Bloch A, Hill MJ, Swaroop SV. Primary prevention of colorectal cancer. Bull World Health Organ 1990;68:377-85.

16. Winawer SJ, Fletcher RH, Miller L, Godlee F, Stolar MH, Mulrow CD, et al. Colorectal cancer screening. Clinical guidelines and rationale. Gastroenterology 1997;112:594 642.

17. Rex DK, Johnson DA, Lieberman DA, Burt RW, Sonnenberg A. Colorectal cancer prevention 2000: screening recommendations of the American College of Gastroenterology. American College of Gastroenterology. Am J Gastroenterol 2000; 95:868-77.

18. Lieberman DA, Weiss DG, Bond JH, Ahnen DJ, Garewal H, Chejfec G. Veterans Affairs Cooperative Study Group. Use of colonoscopy to screen asymptomatic adults for colorectal cancer. N Engl J Med 2000;343:162-8.

19. Imperiale TF, Wagner DR, Lin CY, Larkin GN, Rogge JD, Ransohoff DF. Risk of advanced proximal neoplasms in asymptomatic adults according to the distal colorectal findings. N Engl J Med 2000;343:169-74.

20. Sonnenberg A, Delcr F, Inadomi JM. Cost-effectiveness of colonoscopy in screening for colorectal cancer. Ann Intern Med 2000;133:573-84.

21. Lewis JD. Prevention and treatment of colorectal cancer: pay now or pay later. Ann Intern Med 2000;133:647-9. 
22. Ellis CN, Boggs HW, Slagle GW, Cole PA, Coyle DJ. Clinical significance of diminutive polyps of the rectum and sigmoid colon. Dis Colon Rectum 1993;36:8-9.

23. Pennazio M, Arrigoni A, Risio M, Spandre M, Rossini FP. Small rectosigmoid polyps as markers of proximal neoplasms. Dis Colon Rectum 1993;36:1121-5.

24. Papatheodoridis GV, Triantafyllou K, Tzouvala M, Paspatis G, Xourgias V, Karamanolis DG. Characteristics of rectosigmoid adenomas as predictors of synchronous advanced proximal colon neoplasms. Am J Gastroenterol 1996;91: 1809-13.

25. Schoen RE, Corle D, Cranston L, Weissfeld JL, Lance P, Burt R, et al. The Polyp Prevention Trial. Is colonoscopy needed for the nonadvanced adenoma found on sigmoidoscopy? Gastroenterology 1998;115:533-41.

26. Zarchy TM, Ershoff D. Do characteristics of adenomas on flexible sigmoidoscopy predict advanced lesions on baseline colonoscopy? Gastroenterology 1994;106:1501-4.

27. Sciallero S, Bonelli L, Aste H, Casetti T, Bertinelli E, Bartolini S, et al. Do patients with rectosigmoid adenomas $5 \mathrm{~mm}$ or less in diameter need total colonoscopy? Gastrointest Endosc 1999;50:314-21.

28. Achkar E, Carey W. Small polyps found during fiberoptic sigmoidoscopy in asymptomatic patients. Ann Intern Med 1988;109:880-3.

29. Grossman S, Milos ML, Tekawa IS, Jewell NP. Colonoscopic screening of persons with suspected risk factors for colon cancer. II. Past history of colorectal neoplasms. Gastroenterology 1989;96:299-306.

30. Opelka FG, Timmcke AE, Gathright JB, Ray JE, Hicks TC. Diminutive colonic polyps: an indication for colonoscopy. Dis Colon Rectum 1992;35:178-81.

31. Blue MG, Sivak MV, Achkar E, Matzen R, Stahl RR. Hyperplastic polyps seen at sigmoidoscopy are markers for additional adenomas seen at colonoscopy. Gastroenterology 1991;100:564-6.

32. Thiis-Evensen E, Hoff GS, Sauar J, Majak BM, Vatn MH. Flexible sigmoidoscopy or colonoscopy as a screening modality for colorectal adenomas in older age groups? Findings in a cohort of the normal population aged 63-72 years. Gut 1999; 45:834-9.

33. Wallace MB, Kemp JA, Trnka YM, Donovan JM, Farraye FA. Is colonoscopy indicated for small adenomas found by screening flexible sigmoidoscopy? Ann Intern Med 1998; 129:273-8.

34. Read TE, Read JD, Butterly LF. Importance of adenomas $5 \mathrm{~mm}$ or less in diameter that are detected by sigmoidoscopy. N Engl J Med 1997;336:8-12.

35. Levin TR, Palitz A, Grossman S, Conell C, Finkler L, Ackerson L, et al. Predicting advanced proximal colonic neoplasia with screening sigmoidoscopy. JAMA 1999;281:1611-7.

36. Foutch PG, Mai H, Pardy K, DiSario JA, Manne RK, Kerr D. Flexible sigmoidoscopy may be ineffective for secondary prevention of colorectal cancer in asymptomatic, averagerisk men. Dig Dis Sci 1991;36:924-8.

37. Lieberman DA, Smith FW. Screening for colon malignancy with colonoscopy. Am J Gastroenterol 1991;86:946-51.

38. Rex DK, Lehman GA, Hawes RH, Ulbright TM, Smith JJ. Screening colonoscopy in asymptomatic average-risk persons with negative fecal occult blood tests. Gastroenterology 1991; 100:64-7.

39. O'Brien MJ, Winawer SJ, Zauber AG, Gottlieb LS, Sternberg SS, Diaz B, et al. The National Polyp Study: patient and polyp characteristics associated with high-grade dysplasia in colorectal adenomas. Gastroenterology 1990;98:371-9. 
40. Morson BC, Dawson IMP, Day DW, Jass JR, Price AB, Williams GT. Benign epithelial tumours and polyps. In: Morson BC, Dawson IM, editors. Gastrointestinal pathology. Oxford: Blackwell Scientific; 1991. p. 563-96.

41. Konishi F, Morson BC. Pathology of colorectal adenomas: a colonoscopic survey. J Clin Pathol 1982;35:830-41.

42. Hosmer DW, Lemeshow SA. Applied logistic regression. 2nd ed. New York: Wiley; 2000.

43. Hanley JA, McNeil BJ. The meaning and use of the area under a receiver operating characteristic (ROC) curve. Radiology 1992;143:29-36.

44. Shoenfeld P, Guyatt G, Hamilton F, Laine L, Cook D, Bjorkman D, et al. An evidence-based approach to gastroenterology diagnosis. Gastroenterology 1999;116:1230-7.

45. Takkouche B, Cadarso-Suarez C, Spiegelman D. Evaluation of old and new tests of heterogeneity in epidemiologic studies. Am J Epidemiol 1999;150:206-15.

46. Atkin WS, Morson BC, Cuzick J. Long-term risk of colorectal cancer after excision of rectosigmoid adenomas. N Engl J Med 1992;326:658-62.

47. Johnson DA, Gurney MS, Volpe RJ, Jones DM, VanNess MM, Chobanian SJ, et al. A prospective study of the prevalence of colonic neoplasms in asymptomatic patients with an agerelated risk. Am J Gastroenterol 1990;85:969-74.

48. Dinning JP, Hixson LJ, Clark LC. Prevalence of distal colonic neoplasia associated with proximal colon cancers. Ann Intern Med 1994;154:853-6.

49. Castiglione G, Ciatto S, Mazzotta A, Grazzini G. Sensitivity of screening sigmoidoscopy for proximal colorectal tumours. Lancet 1995;345:726-7.

50. Lemmel GT, Haseman JH, Rex DK, Rahmani E. Neoplasia distal to the splenic flexure in patients with proximal colon cancer. Gastrointest Endosc 1996;44:109-11.

51. Rex DK, Chak A, Vasudeva R, Gross T, Lieberman D, Bhattacharya I, et al. Prospective determination of distal colon findings in average-risk patients with proximal colon cancer. Gastrointest Endosc 1999;49:727-30.

52. Netzer P, Buttiker U, Pfister M, Halter F, Schmassmann A. Frequency of advanced neoplasia in the proximal colon without an index polyp in the rectosigmoid. Dis Colon Rectum 1999;42:661-7.

53. Stern MA, Fendrick AM, McDonnell WM, Gunaratnam N, Moseley R, Chey WD. A randomized, controlled trial to assess a novel colorectal cancer screening strategy: the conversion strategy. Am J Gastroenterol 2000;95:2074-9.

54. Arrigoni A, Pennazio M, Rossini FP. Rectosigmoid polyps as markers of colonic neoplasms: a cost benefit analysis of different diagnostic protocols. Anticancer Res 1995;15:563-8.

55. Zauber A, Winawer SJ, Diaz B. The National Polyp Study (NPS): the association of colonic hyperplastic polyps and adenomas [abstract]. Am J Gastroenterol 1988;83:AB1060.

56. Provenzale D, Garrett JW, Condon SE, Sandler RS. Risk for colon adenomas in patients with rectosigmoid hyperplastic polyps. Ann Intern Med 1990;113:760-3.

57. Rex DK, Smith JJ, Ulbright TM, Lehman GA. Distal colonic hyperplastic polyps do not predict proximal adenomas in asymptomatic average-risk subjects. Gastroenterology 1992; 102:317-9.

58. Brady PG, Straker RJ, McClave SA, Nord HJ, Pinkas M, Robinson BE. Are hyperplastic rectosigmoid polyps associated with an increased risk of proximal colonic neoplasms? Gastrointest Endosc 1993;39:481-5. 
59. Sciallero S, Constantini M, Bertinelli E, Castiglione G, Onofri P, Aste H, et al. Distal hyperplastic polyps do not predict proximal adenomas: results from a multicentric study of colorectal adenomas. Gastrointest Endosc 1997;46:124-30.

60. Bond JH. Polyp guidelines: diagnosis, treatment, and surveillance for patients with nonfamilial colorectal polyps. Ann Intern Med 1993;119:836-43.

61. Selby JV. Targeting colonoscopy. Gastroenterology 1994; 106:1702-5.

62. Sandler RS, Eisen GM, Talal A, Wurzelmann JI. Rational approach to small polyps found on sigmoidoscopy. J Clin Gastroenterol 1995;20:317-20.

63. Tripp MR, Morgan TR, Sampliner RE, Kogan FJ, Protell RL, Earnest DL. Synchronous neoplasms in patients with diminutive colorectal adenomas. Cancer 1987;60:1599-603.

64. Ryan ME, Norfleet RG, Kirchner JP, Parent K, Nunez JF, Rhodes RA, et al. The significance of diminutive colonic polyps found at flexible sigmoidoscopy. Gastrointest Endosc 1989;35:85-9. 


\begin{tabular}{|c|c|}
\hline \multicolumn{2}{|c|}{ Table 1. Frequency of distal colonic polyps in patients with advanced } \\
proximal neoplasia
\end{tabular}

\begin{tabular}{|l|c|c|c|}
\hline Table 2. Predictive value of distal colonic findings for advanced proximal neoplasia \\
\hline $\begin{array}{l}\text { Screening strategies based on } \\
\text { distal colonic findings }\end{array}$ & Sensitivity for APN & LR $(+)$ for APN & $\begin{array}{c}\text { Patients undergoing } \\
\text { colonoscopy }\end{array}$ \\
\hline $\begin{array}{l}\text { Criteria for a positive distal } \\
\text { endoscopic examination }\end{array}$ & $\%(95 \% \mathrm{CI})$ & $\%(95 \% \mathrm{CI})$ & $\%(95 \% \mathrm{CI})$ \\
\hline Endoscopic distal findings & & & \\
\hline Any polyp $\geq 10 \mathrm{~mm}$ & $30.4(19.2-44.3)$ & $7.5(2.35-12.69)$ & $4.7(3.9-5.7)$ \\
\hline Any polyp $>5 \mathrm{~mm}$ & $50.0(36.5-63.5)$ & $4.5(4.2-8.52)$ & $12.2(10.8-13.6)$ \\
\hline Any distal polyp & $62.5(48.5-74.8)$ & $2.1(0.0-4.91)$ & $30.2(28.7-32.6)$ \\
\hline $\begin{array}{l}\text { Endoscopic and histopathologic } \\
\text { distal findings }\end{array}$ & & & \\
\hline Any advanced distal neoplasia & $33.9(22.2-47.9)$ & $7.3(2.21-12.41)$ & $5.4(4.5-6.4)$ \\
\hline Any distal adenoma $>5$ mm & $48.2(35.1-61.3)$ & $5.2(0.83-9.51)$ & $10.8(9.5-12.1)$ \\
\hline Any distal adenoma & $58.9(45.0-71.6)$ & $3.0(0.0-6.41)$ & $20.4(18.7-22.1)$ \\
\hline $\begin{array}{l}\text { Primary screening with } \\
\text { olonoscopy }\end{array}$ & 100 & & 100 \\
\hline
\end{tabular}

APN, Advanced proximal neoplasia; LR, likelihood ratio; CI, confidence interval. 


\begin{tabular}{|l|c|c|c|}
\hline \multicolumn{4}{|c|}{$\begin{array}{r}\text { Table 3. Positive predictive value for advanced proximal neoplasms } \\
\text { according to different distal findings }\end{array}$} \\
\hline Combined endoscopic and pathologic data & Only endoscopic data \\
\hline Distal findings & PPV \% (95\% CI) & Distal findings & PPV \% (95\% CI) \\
\hline Advanced neoplasms & $16.0(10.1-24.1)$ & Polyps $\geq 10 \mathrm{~mm}$ & $16.3(10.1-25.2)$ \\
\hline $\begin{array}{l}\text { Nonadvanced adenomas } \\
>5 \mathrm{~mm} \text { and }<10 \mathrm{~mm}\end{array}$ & $6.7(2.2-11.1)$ & Polyps $>5$ and $<10 \mathrm{~mm}$ & $6.7(3.5-11.9)$ \\
\hline Nonadvanced adenomas $\leq 5 \mathrm{~mm}$ & $1.2(0.2-4.6)$ & Polyps $\leq 5 \mathrm{~mm}$ & $1.7(0.8-3.7)$ \\
\hline No distal adenomas & $1.3(0.8-2.0)$ & No polyps & $1.4(0.9-2.1)$ \\
\hline PPV, Positive predictive value; CI, confidence interval. & \\
\hline
\end{tabular}


Table 4. Risk of advanced proximal neoplasia according to distal endoscopic and histopathologic findings; multivariate models

\begin{tabular}{|c|c|c|}
\hline \multicolumn{3}{|c|}{ Model A: age, gender and endoscopic assessment } \\
\hline \multirow{2}{*}{ Variable } & \multicolumn{2}{|c|}{ Risk of APN } \\
\hline & \% with APN & Adjusted OR (95\% CI) \\
\hline Age (for each year older) & & $1.05(1.02,1.09)$ \\
\hline \multicolumn{3}{|l|}{ Gender } \\
\hline Female & 1.6 & 1 (referent) \\
\hline Male & 2.9 & $1.36(0.64,2.91)$ \\
\hline \multicolumn{3}{|l|}{ Endoscopic assessment } \\
\hline No distal polyps & 1.4 & 1 (referent) \\
\hline \multicolumn{3}{|c|}{ Distal polyps (maximum size) } \\
\hline$\leq 5 \mathrm{~mm}$ & 1.7 & $1.01(0.40,2.57)$ \\
\hline $6-9 \mathrm{~mm}$ & 6.7 & $3.49(1.43,8.51)$ \\
\hline$\geq 10 \mathrm{~mm}$ & 16.3 & $9.28(4.08,21.10)$ \\
\hline \multicolumn{3}{|l|}{ Distal polyps (number) } \\
\hline No distal polyps & 1.4 & 1 (referent) \\
\hline 1 distal polyp & 3.8 & see "maximum size" \\
\hline 2 distal polyps & 4.3 & \\
\hline$\geq 3$ distal polyps & 9.5 & $1.80(0.80,4.06)$ \\
\hline \multicolumn{3}{|c|}{$\begin{array}{l}\text { Note: In a patient with two distal polyps, the largest of which is }>10 \mathrm{~mm} \text {, the OR for APN would be } 1.06 \\
\times 9.28 \text {. } \\
\text { APN, Advanced proximal neoplasia; OR, odds ratio; CI, confidence interval. }\end{array}$} \\
\hline \multicolumn{3}{|c|}{ Model B: age, gender, endoscopic and histopathologic assessment } \\
\hline & \multicolumn{2}{|c|}{ Risk of APN } \\
\hline Variable (distal findings) & \% with APN & Adjusted OR ${ }^{\dagger}(95 \%$ CI \\
\hline \multicolumn{3}{|c|}{ Combined endoscopic and histopathologic assessment } \\
\hline No distal polyps & 1.4 & 1 (referent) \\
\hline Hyperplastic only & 0.0 & $0.01(-)$ \\
\hline Fulgurated polyps only & 0.7 & $0.45(0.06,3.38)$ \\
\hline \multicolumn{3}{|l|}{ Adenomas (type) } \\
\hline \multicolumn{3}{|l|}{ Nonadvanced } \\
\hline$\leq 5 \mathrm{~mm}$ & 2.8 & $1.52(0.58,3.97)$ \\
\hline $6-9 \mathrm{~mm}$ & 6.7 & $3.00(1.78,7.68)$ \\
\hline Advanced $^{\ddagger}$ & 16.0 & $7.30(3.28,16.25)$ \\
\hline \multicolumn{3}{|l|}{ Adenomas (number) } \\
\hline 1 adenoma & 4.9 & see "type" \\
\hline 2 adenoma & 9.6 & $1.81(0.74,4.44)$ \\
\hline$\geq 3$ adenomas & 19.1 & $2.65(1.03,6.86)$ \\
\hline \multicolumn{3}{|c|}{$\begin{array}{l}\text { †Odds ratios shown in each model are adjusted for age, gender, and all other variables presented in the } \\
\text { model. } \\
{ }^{\ddagger} \text { Adenoma } \geq 10 \mathrm{~mm} \text {, with villous component or with severe dysplasia or invasive cancer. }\end{array}$} \\
\hline
\end{tabular}


Table 5. Prediction of advanced proximal neoplasms according to different screening strategies based upon distal findings.

\begin{tabular}{|c|c|}
\hline Variables in the model & $\begin{array}{c}\text { Area under the ROC } \\
\text { curve, \% (95\% CI) }\end{array}$ \\
\hline Baseline model: age and gender only & $66.4(61.6,71.1)$ \\
\hline $\begin{array}{l}\text { Endoscopic models (adjusted for age and } \\
\text { gender) }\end{array}$ & $73.8(67.3,80.3)$ \\
\hline Any distal polyp & $78.2(71.8,84.7)$ \\
\hline Any distal polyp $>5$ mm & $74.6(67.4,81.7)$ \\
\hline Any distal polyp $\geq 10$ mm & $78.6(72.1,85.1)$ \\
\hline $\begin{array}{l}\text { Maximum predictive potential (size and } \\
\text { number of distal polyps) }\end{array}$ & $77.0(70.6,83.3)$ \\
\hline $\begin{array}{l}\text { Combined endoscopic and histopathologic } \\
\text { models (adjusted for age and gender) }\end{array}$ & $77.7(70.8,84.7)$ \\
\hline Any distal adenoma or cancer & $75.6(68.6,82.6)$ \\
\hline Any distal adenoma $>5$ mm & $79.7(73.1,86.2)$ \\
\hline $\begin{array}{l}\text { Any advanced distal neoplasm } \\
\text { Mistopathology, dysplasia, and number of } \\
\text { distal neoplasms) }\end{array}$ & Receiver operating characteristic; CI, confidence interval. \\
\hline ROC, & \\
\hline
\end{tabular}




\begin{tabular}{|c|c|c|c|c|}
\hline \multicolumn{5}{|c|}{$\begin{array}{l}\text { Table 6. Comparison of the studies of the sensitivity of sigmoidoscopy in the } \\
\text { detection of advanced neoplasms in colon }\end{array}$} \\
\hline \multirow{4}{*}{ Study } & \multicolumn{4}{|c|}{ Patients with APN } \\
\hline & Total & $\begin{array}{c}\text { Any distal } \\
\text { polyp }\end{array}$ & $\begin{array}{c}\text { Any distal } \\
\text { adenoma }\end{array}$ & $\begin{array}{l}\text { Any distal } \\
\text { advanced }\end{array}$ \\
\hline & \multirow[b]{2}{*}{$\mathrm{N}$} & \multicolumn{3}{|c|}{$\mathrm{N}$} \\
\hline & & \multicolumn{3}{|c|}{ Sensitivity, \% $(95 \% \mathrm{CI})$} \\
\hline \multirow[t]{2}{*}{ Lieberman (19) } & 128 & 80 & 62 & 27 \\
\hline & & $62.5(53.5-70.8)$ & $48.4(39.6-57.4)$ & $21.1(14.6-29.4)$ \\
\hline \multirow[t]{2}{*}{ Imperiale $(20)^{*}$} & 50 & 27 & 19 & 7 \\
\hline & & $54.0(39.5-67.9)$ & $33.0(25.0-52.8)$ & $14.0(6.3-27.4)$ \\
\hline \multirow[t]{2}{*}{ Present study } & 56 & 35 & 33 & 19 \\
\hline & & $62.5(48.5-74.8)$ & $58.9(45.0-71.6)$ & $33.9(22.2-47.9)$ \\
\hline $\begin{array}{c}\text { Summary of } \\
\text { sensitivity } \\
\text { (pooled estimate) }\end{array}$ & & $61.1(54.9-68.0)^{\dagger}$ & $50.1(43.8-57.4)^{\ddagger}$ & $24.4(14.8-36.1)^{\S}$ \\
\hline \multicolumn{5}{|c|}{$\begin{array}{l}\text { APN, Advanced proximal neoplasms }(\geq 10 \mathrm{~mm} \text { and/or villous and/or severe } \\
\text { dysplasia or invasive cancer); CI, confidence interval. } \\
\text { *In the study of Imperiale et al., size } \geq 10 \mathrm{~mm} \text { was not considered a feature of } \\
\text { advanced adenoma. } \\
\text { A lack of significant heterogeneity in the } Q \text { test was taken as indicating that a } \\
\text { fixed effect model was appropriate for the summing-up. Test for heterogeneity } \\
\text { (pooled estimate): } \\
\text { Sensitivity }{ }^{\dagger}, p=0.64 \text {; Sensitivity }{ }^{\ddagger}, p=0.13 \text {; Sensitivity }{ }^{\S}, p=0.06 \text {. }\end{array}$} \\
\hline
\end{tabular}

